\section{Review Article}

\section{Check for updates}

\section{OPEN ACCESS}

Received: Jun 23, 2017

Accepted: Aug 20, 2017

\section{Correspondence to}

\section{Gianlorenzo Dionigi}

Division of Endocrine Surgery, Department of Human Pathology in Adulthood and Childhood "G. Barresi”, University Hospital G. Martino, University of Messina, Via C. Valeria 1, Messina 98125, Italy.

Tel: +39-090-2212637

Fax: +39-090-2212611

E-mail: gdionigi@unime.it

Hui Sun

Division of Thyroid Surgery, Jilin Provincial Key Laboratory of Surgical Translational Medicine, China-Japan Union Hospital of Jilin University, 126 Xiantai St, Erdao Qu, Changchun 130033, China.

Tel: +86-431-8499-5999

Fax: +86-437-8464-1026

E-mail: thyroidjl@163.com

Copyright (c) 2017. Korean Association of Thyroid and Endocrine Surgeons; KATES This is an Open Access article distributed under the terms of the Creative Commons Attribution Non-Commercial License (https:// creativecommons.org/licenses/by-nc/4.0/).

ORCID IDS

Hoon Yub Kim iD

https://orcid.org/0000-0002-6731-3912 Hui Sun (iD

https://orcid.org/0000-0002-1324-3808

Young Jun Chai (D)

https://orcid.org/0000-0001-8830-3433

\title{
Loss of the Neuromonitoring Signal on the First Side in Planned Total Thyroidectomy
}

\author{
Hoon Yub Kim (iD) 1 , Hui Sun (1D) 2 , Young Jun Chai (iD ${ }^{3}$, Ralph Tufano (i) ${ }^{4}$, \\ Henning Dralle $\mathbb{C}^{5}$, Giuseppe Navarra ${ }^{(1)}{ }^{6}$, Gianlorenzo Dionigi $(1){ }^{6}$, \\ the Korean Intraoperative Neural Monitoring Society (KINMOS)
}

${ }^{1}$ KUMC Thyroid Center, Korea University Anam Hospital, Seoul, Korea

${ }^{2}$ Division of Thyroid Surgery, Jilin Provincial Key Laboratory of Surgical Translational Medicine, China-Japan Union Hospital of Jilin University, Changchun, China

${ }^{3}$ Department of Surgery, Seoul Metropolitan Government-Seoul National University Boramae Medical Center, Seoul, Korea

${ }^{4}$ Department of Otolaryngology-Head and Neck Surgery, The Johns Hopkins University School of Medicine, Baltimore, MD, USA

${ }^{5}$ Department of General, Visceral, and Transplantation Surgery, University Hospital Essen, Essen, Germany ${ }^{6}$ Division of Endocrine Surgery, Department of Human Pathology in Adulthood and Childhood "G. Barresi", University Hospital G. Martino, University of Messina, Messina, Italy

\section{ABSTRACT}

With an increased use of intraoperative neural monitoring (IONM), an adaptation of the resection strategy appears to be necessary in case of an intraoperative loss of signal (LOS) of the first operated side with total thyroidectomy planned. The contralateral side resection with intact recurrent laryngeal nerve (RLN) function from the surgical point of view, basically has 3 options: 1) no contralateral resection in bilateral goiter, Graves' disease, or low risk thyroid carcinoma (differentiated and medullary thyroid carcinomas) with the aim of 2-stage completion surgery after recovery of nerve function; 2) contralateral subtotal resection ventrally of the RLN plane in benign goiter with a safety distance to the nerve with the aim of avoiding further surgery; and 3) total thyroidectomy as planned for advanced thyroid carcinomas (including undifferentiated thyroid carcinomas) with the aim of immediate postoperative radioiodotherapy. The following document provides a synopsis of the experiences of the Korean Intraoperative Neural Monitoring Society (KINMoS) for the strategy for planned total thyroidectomy and loss of the neuromonitoring signal on the first thyroid lobe.

Keywords: Thyroid neoplasms; Surgery; Recurrent laryngeal nerve; Nerve injury; Stage thyroidectomy

\section{INTRODUCTION}

Tracheotomy due to bilateral vocal cord palsy (BVCP) is one of the most feared complications in thyroid surgery (1). Patients with bilateral cord paralysis may develop severe symptoms such as breathlessness, stridor and aspiration (2,3). Breathlessness and stridor indicate upper airway obstruction (4). Aspiration can be due to alteration in the sensory innervation supplying the laryngeal mucosa or ineffective motor innervation to the laryngeal muscles during laryngeal closure (1-5). 
Ralph Tufano iD

https://orcid.org/0000-0002-2219-3208

Henning Dralle iD

https://orcid.org/0000-0003-4710-8193

Giuseppe Navarra (iD

https://orcid.org/0000-0003-0372-1615

Gianlorenzo Dionigi (ID

https://orcid.org/0000-0003-0864-6087

Author Contributions

Conceptualization: Hoon Yub Kim, Hui Sun,

Young Jun Chai, Ralph P. Tufano, Henning

Dralle, Giuseppe Navarra, Gianlorenzo Dionigi;

Data curation: Hoon Yub Kim, Hui Sun, Young

Jun Chai; Formal analysis: Gianlorenzo Dionigi;

Funding acquisition: Hui Sun; Investigation:

Gianlorenzo Dionigi; Methodology: Hoon

Yub Kim, Hui Sun, Young Jun Chai; Project

administration: Hoon Yub Kim, Hui Sun, Young

Jun Chai; Resources: Gianlorenzo Dionigi;

Software: Gianlorenzo Dionigi; Supervision:

Gianlorenzo Dionigi; Validation: Hoon Yub

Kim, Hui Sun, Young Jun Chai, Ralph P.

Tufano, Henning Dralle, Giuseppe Navarra,

Gianlorenzo Dionigi; Visualization: Hoon

Yub Kim, Hui Sun, Young Jun Chai, Ralph P.

Tufano, Henning Dralle, Giuseppe Navarra,

Gianlorenzo Dionigi; Writing - original draft:

Gianlorenzo Dionigi; Writing - review \& editing:

Hoon Yub Kim, Hui Sun, Young Jun Chai, Ralph

P. Tufano, Henning Dralle, Giuseppe Navarra,

Gianlorenzo Dionigi.

Conflict of Interest

No potential conflict of interest relevant to this article was reported.
Although intraoperative neural monitoring (IONM) has been used as a gold standard for the functional control of the recurrent laryngeal nerve (RLN), unexpected intraoperative failures of the electromyography (EMG) signal (i.e., loss of signal [LOS]) cannot be avoided (6).

However, the prediction of the early postoperative vocal function is imprecise for the IONM due to a predominantly low and very variable positive predictive value of $10 \%-90 \%(7,8)$. This lack of diagnostic precision as well as the fundamental possibility of intraoperative normalization of the EMG signal as an expression of a recovering RLN function leaves doubts about the widely favored strategy change with termination of the surgery on the affected side in LOS and intended bilateral procedure (6-8).

The intraoperative resection strategy in planned total thyroidectomy and LOS is to be subjected to a critical analysis with the aim of developing a therapy algorithm depending on the anticipated early postoperative vocal fold function (9).

The following document provides a review and a synopsis of the experiences of the Korean Intraoperative Neural Monitoring Society (KINMoS) for the strategy for planned total thyroidectomy and loss of the neuromonitoring signal on the first thyroid lobe.

\section{INTRAOPERATIVE LOS AND ERROR SEARCH}

In general, the rare but feared complication of postoperative BVCP and the resulting difficulty of achieving statistical significance make very difficult to demonstrate the superiority of the IONM to the reduction of postoperative paresis rates in comparison to only visual RLN identification $(7,10-15)$.

Only Barczyński et al. (16) demonstrated a significant superiority of the IONM in a prospective randomized study of 1,000 nerves with a reduction of the early postoperative nerve palsy rate in high risk procedures (i.e., Graves, re-do surgery, cancer, etc.) compared to the sole optical nerve presentation.

Furthermore, the vagal stimulation (V1 and V2) versus the single RLN stimulation (R1 and R2) is superior with regard to the prediction of the postoperative RLN function $(7,8)$.

Interestingly, a current German-wide survey of 1,119 surgical clinics demonstrates an application of the IONM in over $90 \%$ of all thyroidectomies (12). Routine vagal stimulation was used in pre-resection (V1) in 50\% and post-resection (V2) in 70\% of cases (12).

Figures published in the USA and Italy confirm the now widely accepted IONM in thyroid surgery $(17,18)$. The IONM is used regularly in more than $80 \%$ of all ear, nose, and throat (ENT) hospitals surveyed, as well as almost $20 \%$ to $50 \%$ of all surgical departments $(17,18)$.

In addition to the increase in intraoperative safety and the facilitation of the operative procedure, particularly in the case of high-risk interventions, more and more medical legal aspects are being considered $(9,19)$.

This results in 2 essential requirements for the surgeon: 1) an experienced handling of neuromonitoring technology; and 2) the intraoperative adaptation of the resection strategy in the case of an LOS on the first (dominant) operated side (9). 
Although not sufficiently understood the pathophysiological context, 2 different electrophysiologically distinct lesions in the anatomically intact RLN have been described and discussed in the literature $(20,21)$. In contrast to the global nerve damage (type 2), an electrophysiologically altered segment with regular stimulability can be located distal to the lesion in segmental injury (type 1) $(20,21)$. The direct, segmental damage mechanism in type 1 injuries is caused by mechanical as traction and compressive forces, ligatures or thermal lesions near the RLN. The few literature data on the incidence of type 1 or type 2 injuries vary between $25 \%-69 \%$ or $31 \%-75 \%(20,21)$. In almost $80 \%$ of cases, mechanical factors (as traction) could be detected, whereas only $7 \%$ of the cases were caused by bipolar coagulation (20-24). In 15\% of the cases, the cause remained unclear (20-24). In 80\% of the cases, real time examinations with the use of continuous neuromonitoring also show traction as the triggering factor of an impending LOS (20). Almost all type 2 lesions were traction-induced in this study, but in exceptional cases no cause could be found $(9,20)$. In the case of the segmental nerve lesions, damage was caused by traction, also by bipolar coagulation, more than $80 \%$ in the area of the intersection of the nerve with the inferior thyroid artery, or distal to the laryngotracheal nerve entrance $(9,20-24)$. The anatomical region of the Berry ligament appears to be a predilection site for a functional disorder of the RLN, especially in early extralaryngeal division with markedly increased vulnerability of the motoneurons running in the anterior branch $(9,20-24)$.

In the case of an ipsilaterally derivable stimulation signal and EMG of the vagal nerve after resection of the thyroid gland, the prediction of an intact postoperative RLN function of $92 \%-100 \%$ is very high [7]. In contrast, the positive predictive value is low and ranges between $10 \%$ and $90 \%$ (7). This high proportion of false-positive findings-LOS and regular early-postoperative RLN function can be favorably influenced by a comprehensive intraoperative error search $(7,9)$.

As recommended by the International Intraoperative Monitoring Study Group, the systematic review of the IONM system at LOS is mandatory (6). When the ipsilateral laryngeal musculature is triggered by nerve stimulation ("laryngeal twitch") and in the case of a non-stimulable contralateral vagus nerve, a technical disturbance must be found in the area of the measuring procedure, i.e., recording site (6). In the absence of the ipsilateral "laryngeal twitch," a technical disturbance in the area of the stimulation process should be excluded, i.e., stimulating site (6). The absence of the ipsilateral "laryngeal twitch" despite the fact that the contralateral vagus nerve can be stimulated is indicative of a true functional disorder of the ipsilateral RLN (6).

\section{INTRAOPERATIVE STRATEGY CHANGE AFTER LOS OF THE FIRST OPERATED SIDE}

An LOS with anatomically intact RLN does not have an effect on the operative resection strategy in the case of a planned 1-sided thyroid procedure. The situation is very different in the case of LOS of the initially operated side with planned bilateral thyroidectomy. The IONM is indispensable for the elimination of the risk of a BVCP (25).

As previously shown, BVCP was significantly reduced $(\mathrm{P}=0.017)$ in case of LOS of the first side and termination of surgery without contralateral resection (26). Thus, $94 \%$ of the surgeons from 1,119 clinics surveyed in Germany would change their resection strategy with regard to 


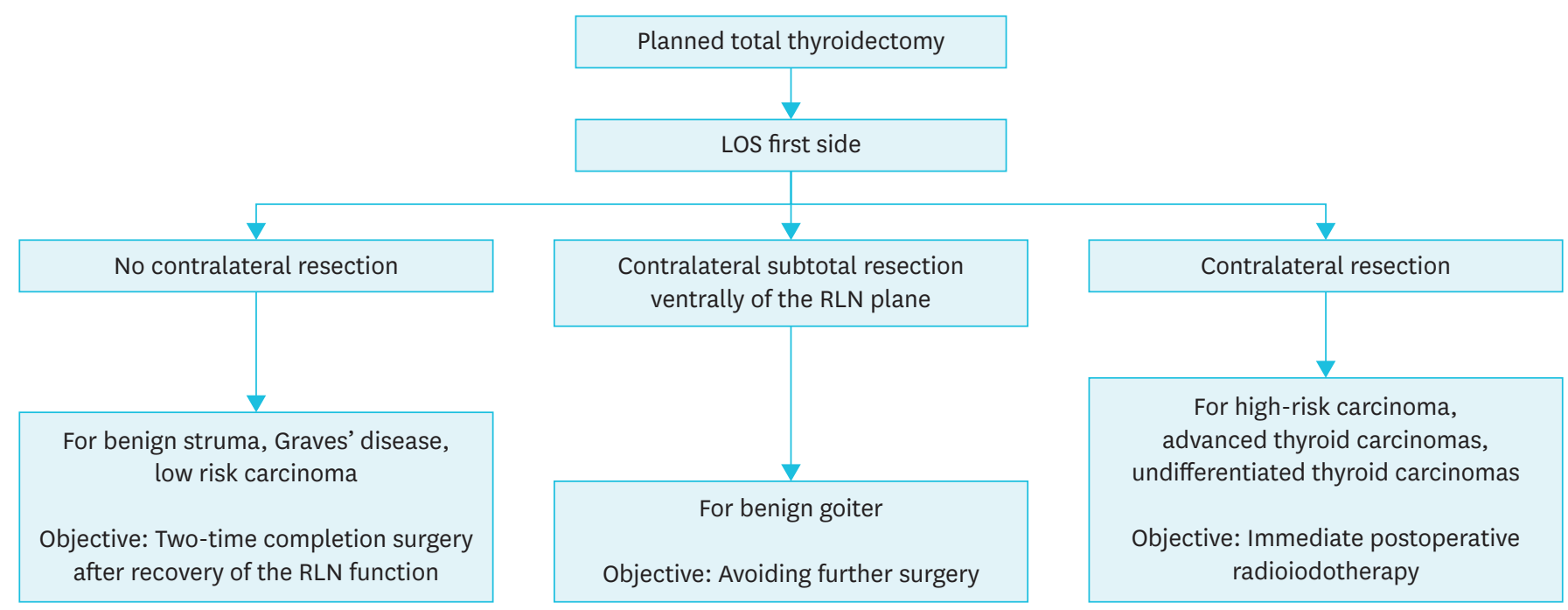

Fig. 1. Surgical options for planned total thyroidectomy and intraoperative signal loss on the first operated side. LOS = loss of signal; RLN = recurrent laryngeal nerve.

the second side after LOS on the first operated side: $85 \%$ would definitively end the resection with the first page or $9 \%$ reduce the resection extent of the contralateral side, only $6 \%$ would continue to resect both sides as planned $(9,12)$.

An adaptation of the resection strategy appears to be necessary $(9,12,26)$. In the case of an intraoperative LOS of the first operated side with total thyroidectomy planned, the contralateral side with intact RLN function from the surgical point of view basically has 3 options, which serve as a therapy algorithm summarized in Fig. $1(9,12,26)$.

1. No contralateral resection in bilateral goiter, Graves' disease, or low risk thyroid carcinoma (differentiated and medullary thyroid carcinomas) with the aim of 2-stage completion surgery after recovery of nerve function.

2. Contralateral subtotal resection ventrally of the RLN plane in benign goiter with a safety distance to the nerve with the aim of avoiding further surgery.

3. Total thyroidectomy as planned for advanced thyroid carcinomas (including undifferentiated thyroid carcinomas) with the aim of immediate postoperative radioiodotherapy.

A literature review on the operative strategy change in the case of planned total thyroid resection and LOS on the first page is presented in Table 1. The analysis of the data reveals the two fundamental dilemmas of the intraoperative control of the nervous function:

1. False negative findings with intact IONM and postoperative vocal cord palsy. Although rare, these pathological changes in the vocal fold function cannot be detected by the IONM, as in particular the data from Périé et al. (27) with BVCP in 2 patients. It is therefore more important that bilateral resection should be minimized.

2. False-positive findings with LOS and regular postoperative vocal cord function. The recently published alternative strategy of waiting for intraoperative signal recovery and contralateral continuation of the planned operation is based on a signal recovery in $90 \%$ of cases within 20 
Table 1. Summary of the intraoperative resection strategy and the postoperative vocal cord function in case of planned total thyroidectomy and signal loss on the first operated side

\begin{tabular}{|c|c|c|c|c|c|c|c|c|c|}
\hline \multirow[t]{2}{*}{ Literature reference } & \multirow{2}{*}{$\begin{array}{c}\text { Planned } \\
\text { bilateral } \\
\text { thyroidectomy }\end{array}$} & \multicolumn{4}{|c|}{$\begin{array}{l}\text { Strategy after LOS } \\
\text { on the first side }\end{array}$} & \multicolumn{2}{|c|}{$\begin{array}{l}\text { Early postoperative VCP } \\
\text { on the first side }\end{array}$} & \multirow{2}{*}{$\begin{array}{c}\text { Early } \\
\text { postoperative } \\
\text { bilateral SLP }\end{array}$} & \multirow{2}{*}{$\begin{array}{l}\text { Completion } \\
\text { of the second } \\
\text { side }\end{array}$} \\
\hline & & $\begin{array}{l}\text { No. of } \\
\text { patients }\end{array}$ & $\begin{array}{c}\text { Contralateral } \\
\text { hemithyroidectomy }\end{array}$ & $\begin{array}{c}\text { Contralateral } \\
\text { subtotal } \\
\text { resection }\end{array}$ & $\begin{array}{c}\text { No } \\
\text { contralateral } \\
\text { resection }\end{array}$ & $\begin{array}{c}\text { No. of } \\
\text { patients }\end{array}$ & $\begin{array}{c}\text { No. of } \\
\text { false negative } \\
\text { diagnoses }\end{array}$ & & \\
\hline Goretzki et al. [11] & 1,321 & $36(2.7)$ & 16 & 5 & 15 & $32(2.4)$ & 2 & $3(0.2)$ & 9 \\
\hline Périé et al. [27] & 100 & $4(4.0)$ & 0 & 0 & 4 & $6(6.0)$ & 2 & $2(2.0)$ & 3 \\
\hline Sadowski et al. [13] & 220 & $9(4.1)$ & 0 & 0 & 9 & $7(3.2)$ & 0 & - & 8 \\
\hline Sitges-Serra et al. [28] & 290 & $16(5.5)$ & 14 & 2 & 0 & $10(3.4)$ & 6 & $0(0)$ & - \\
\hline Schneider et al. [9] & 1,049 & $27(2.6)$ & 11 & 4 & 12 & $26(2.5)$ & 5 & $0(0)$ & 9 \\
\hline
\end{tabular}

Values are presented as number of patients or number of patients (\%).

LOS = loss of signal; VCP = vocal cord paralysis; SLP = speech-language pathologist.

minutes (28). However, a share of false-positive results of $85 \%$ inevitably raises the question of sufficient troubleshooting. An operation abort after completion of the resection on the first operated side would then indeed be associated with an excessively high proportion of unnecessary 2-stage thyroidectomies. It is also questionable to what extent the time of the LOS and the time up to the signal recovery can be predicted with intermittent neuromonitoring. The clarification of these 2 aspects and the definition of the signal recovery are reserved for further studies on continuous neuromonitoring (20).

In a study, more than $80 \%$ of the functionally impaired RLNs show a complete function recovery within the first 75 days after injury, so that the 2-day completion operation can be carried out without risk of a BVCP after 3 months (9). A comparable complete recovery of the nervous function after 3 to 12 months is described in the literature $(12,13,25,29)$.

Moreover, a complete contralateral resection and LOS on the initially operated side in advanced thyroid carcinomas is technically possible by an experienced surgeon (9). However, such a procedure should be discussed in detail with the patient and balanced against the possibility of a 2-stage procedure. In agreement with other authors there is also no increased morbidity in oncologic view in most thyroid carcinomas, so that the risk of a BVCP can be practically excluded.

\section{CONCLUSION}

IONM is an essential part of the gold standard for the visualization and functional testing of the recurrent nerve during surgery. With increasing attention to medical legal aspects, this device requires an experienced handling of the technology as well as an intraoperative adaptation of the resection strategy in case of loss of the EMG signal on the initially operated side with planned bilateral thyroidectomy. With a LOS, there is an almost $80 \%$ risk of early postoperative vocal palsy. In this case, the further procedure has to be weighed very precisely depending on the underlying thyroid disease of the patient and the surgeon's expertise. The therapeutic algorithm developed here opens up 3 surgical options after LOS on the first operated side. Since more than $80 \%$ of the nervous system disorders completely regress, a 2 -time procedure is absolutely recommended. High false-positive rates should give reason to critically review the clinic-internal standards in order to avoid unnecessary double-stage thyroidectomy. A possible intraoperative recovery of the EMG signal and its importance for the progress of the operation should be the subject of further studies using continuous neuromonitoring. 
Exceptional situations in advanced thyroid carcinomas must be discussed extensively with the patient before surgery.

\section{REFERENCES}

1. Hermann M, Keminger K, Kober F, Nekahm D. Risk factors in recurrent nerve paralysis: a statistical analysis of 7566 cases of struma surgery. Chirurg 1991;62:182-7.

PUBMED

2. Rosato L, Avenia N, Bernante P, De Palma M, Gulino G, Nasi PG, et al. Complications of thyroid surgery: analysis of a multicentric study on 14,934 patients operated on in Italy over 5 years. World J Surg 2004;28:271-6. PUBMED | CROSSREF

3. Gilony D, Gilboa D, Blumstein T, Murad H, Talmi YP, Kronenberg J, et al. Effects of tracheostomy on wellbeing and body-image perceptions. Otolaryngol Head Neck Surg 2005;133:366-71. PUBMED | CROSSREF

4. Hirano M, Ohala J, Vennard $\mathrm{W}$. The function of laryngeal muscles in regulating fundamental frequency and intensity of phonation. J Speech Hear Res 1969;12:616-28. PUBMED | CROSSREF

5. Nouraei SA, Whitcroft K, Patel A, Chatrath P, Sandhu GS, Kaddour H. Impact of unilateral vocal fold mobility impairment on laryngopulmonary physiology. Clin Otolaryngol 2014;39:210-5. PUBMED | CROSSREF

6. Randolph GW, Dralle H, International Intraoperative Monitoring Study GroupAbdullah H, Barczynski $\mathrm{M}$, Bellantone R, et al. Electrophysiologic recurrent laryngeal nerve monitoring during thyroid and parathyroid surgery: international standards guideline statement. Laryngoscope 2011;121 Suppl 1:S1-16. PUBMED | CROSSREF

7. Dralle H, Sekulla C, Lorenz K, Brauckhoff M, Machens AGerman IONM Study Group. Intraoperative monitoring of the recurrent laryngeal nerve in thyroid surgery. World J Surg 2008;32:1358-66. PUBMED | CROSSREF

8. Hermann M, Hellebart C, Freissmuth M. Neuromonitoring in thyroid surgery: prospective evaluation of intraoperative electrophysiological responses for the prediction of recurrent laryngeal nerve injury. Ann Surg 2004;240:9-17. PUBMED | CROSSREF

9. Schneider R, Lorenz K, Sekulla C, Machens A, Nguyen-Thanh P, Dralle H. Surgical strategy during intended total thyroidectomy after loss of EMG signal on the first side of resection. Chirurg 2015;86:154-63. PUBMED | CROSSREF

10. Pemberton JD. Exophthalmic goiter: indications for the stage-operation. Arch Surg 1929;18:735-44. CROSSREF

11. Goretzki PE, Schwarz K, Brinkmann J, Wirowski D, Lammers BJ. The impact of intraoperative neuromonitoring (IONM) on surgical strategy in bilateral thyroid diseases: is it worth the effort? World J Surg 2010;34:1274-84. PUBMED | CROSSREF

12. Dralle H, Sekulla C, Lorenz K, Nguyen Thanh P, Schneider R, Machens A. Loss of the nerve monitoring signal during bilateral thyroid surgery. Br J Surg 2012;99:1089-95. PUBMED | CROSSREF

13. Sadowski SM, Soardo P, Leuchter I, Robert JH, Triponez F. Systematic use of recurrent laryngeal nerve neuromonitoring changes the operative strategy in planned bilateral thyroidectomy. Thyroid 2013;23:329-33. PUBMED | CROSSREF

14. Dionigi G, Barczynski M, Chiang FY, Dralle H, Duran-Poveda M, Iacobone M, et al. Why monitor the recurrent laryngeal nerve in thyroid surgery? J Endocrinol Invest 2010;33:819-22. PUBMED | CROSSREF

15. Henry BM, Graves MJ, Vikse J, Sanna B, Pękala PA, Walocha JA, et al. The current state of intermittent intraoperative neural monitoring for prevention of recurrent laryngeal nerve injury during thyroidectomy: a PRISMA-compliant systematic review of overlapping meta-analyses. Langenbecks Arch Surg 2017;402:663-73. PUBMED | CROSSREF

16. Barczyński M, Konturek A, Cichoń S. Randomized clinical trial of visualization versus neuromonitoring of recurrent laryngeal nerves during thyroidectomy. Br J Surg 2009;96:240-6.

PUBMED | CROSSREF 
17. Ho Y, Carr MM, Goldenberg D. Trends in intraoperative neural monitoring for thyroid and parathyroid surgery amongst otolaryngologists and general surgeons. Eur Arch Otorhinolaryngol 2013;270:2525-30. PUBMED | CROSSREF

18. Dionigi G, Lombardi D, Lombardi CP, Carcoforo P, Boniardi M, Innaro N, et al. Intraoperative neuromonitoring in thyroid surgery: a point prevalence survey on utilization, management, and documentation in Italy. Updates Surg 2014;66:269-76.

PUBMED | CROSSREF

19. Dralle H, Lorenz K, Machens A. Verdicts on malpractice claims after thyroid surgery: emerging trends and future directions. Head Neck 2012;34:1591-6. PUBMED | CROSSREF

20. Schneider R, Randolph GW, Sekulla C, Phelan E, Thanh PN, Bucher M, et al. Continuous intraoperative vagus nerve stimulation for identification of imminent recurrent laryngeal nerve injury. Head Neck 2013;35:1591-8. PUBMED | CROSSREF

21. Chiang FY, Lee KW, Chen HC, Chen HY, Lu IC, Kuo WR, et al. Standardization of intraoperative neuromonitoring of recurrent laryngeal nerve in thyroid operation. World J Surg 2010;34:223-9. PUBMED | CROSSREF

22. Chiang FY, Lu IC, Kuo WR, Lee KW, Chang NC, Wu CW. The mechanism of recurrent laryngeal nerve injury during thyroid surgery--the application of intraoperative neuromonitoring. Surgery 2008;143:743-9. PUBMED | CROSSREF

23. Snyder SK, Lairmore TC, Hendricks JC, Roberts JW. Elucidating mechanisms of recurrent laryngeal nerve injury during thyroidectomy and parathyroidectomy. J Am Coll Surg 2008;206:123-30. PUBMED | CROSSREF

24. Dionigi G, Alesina PF, Barczynski M, Boni L, Chiang FY, Kim HY, et al. Recurrent laryngeal nerve injury in video-assisted thyroidectomy: lessons learned from neuromonitoring. Surg Endosc 2012;26:2601-8. PUBMED | CROSSREF

25. Dionigi G, Frattini F. Staged thyroidectomy: time to consider intraoperative neuromonitoring as standard of care. Thyroid 2013;23:906-8. PUBMED | CROSSREF

26. Melin M, Schwarz K, Lammers BJ, Goretzki PE. IONM-guided goiter surgery leading to two-stage thyroidectomy--indication and results. Langenbecks Arch Surg 2013;398:411-8. PUBMED | CROSSREF

27. Périé S, Aït-Mansour A, Devos M, Sonji G, Baujat B, St Guily JL. Value of recurrent laryngeal nerve monitoring in the operative strategy during total thyroidectomy and parathyroidectomy. Eur Ann Otorhinolaryngol Head Neck Dis 2013;130:131-6. PUBMED | CROSSREF

28. Sitges-Serra A, Fontané J, Dueñas JP, Duque CS, Lorente L, Trillo L, et al. Prospective study on loss of signal on the first side during neuromonitoring of the recurrent laryngeal nerve in total thyroidectomy. $\mathrm{Br}$ J Surg 2013;100:662-6. PUBMED | CROSSREF

29. Dionigi G, Boni L, Rovera F, Rausei S, Castelnuovo P, Dionigi R. Postoperative laryngoscopy in thyroid surgery: proper timing to detect recurrent laryngeal nerve injury. Langenbecks Arch Surg 2010;395:327-31. PUBMED | CROSSREF

30. Cooper DS, Doherty GM, Haugen BR, Kloos RT, Lee SL, Mandel SJ, et al. Revised American Thyroid Association management guidelines for patients with thyroid nodules and differentiated thyroid cancer. Thyroid 2009;19:1167-214.

PUBMED | CROSSREF 